\title{
Tissue Plasminogen Activator in a Vertebral Artery Dissection
}

\author{
Andrew P. Gasecki, Carmelo Graffagnino and Vladimir Hachinski
}

\begin{abstract}
Background: Spontaneous dissection of the vertebral artery is uncommon. Method: Case study. Results: We report a 49-year-old woman who presented with the rapidly progressing basilar artery syndrome who was given an intravenous dose of tissue plasminogen activator seven hours after the onset of first symptoms. Thirty minutes after the injection, a dramatic recovery of the patient's consciousness and neurological signs was noted. Conclusion: To our knowledge, this is the first reported case of intravenous tissue plasminogen activator use in acute vertebral artery dissection.
\end{abstract}

\begin{abstract}
RÉSUMÉ: Activateur du plasminogène tissulaire dans un cas de dissection de l'artère vertébrale. Introduction: La dissection spontanée de l'artère vertébrale est rare. Méthode: Étude de cas. Résultats: Nous rapportons le cas d'une femme de 49 ans qui a consulté pour un syndrome de l'artère basilaire qui progressait rapidement. On lui a administré une dose d'activateur du plasminogène tissulaire sept heures après le début des symptômes. Trente minutes après l'injection, on a noté une amélioration dramatique du niveau de conscience et des signes neurologiques. Conclusion: À notre connaissance, il s'agit du premier cas d'administration intraveineuse de t-PA dans la dissection aiguë de l'artère vertébrale.
\end{abstract}

Can. J. Neurol. Sci. 1997; 24: 151-154

Vertebral artery (VA) dissections have been reported with increasing frequency. ${ }^{1-6}$ The dissection occurs when blood enters a vessel wall, through an intimal tear, resulting in an intramural hematoma which may compress and distort the lumen. Local thrombosis of the artery with subsequent distal embolization may lead to ischemic strokes. Anticoagulants have been generally advocated in symptomatic dissections. ${ }^{7}$ Considerable literature has been accrued on use of thrombolytics in acute myocardial infarction and stroke but, thus far, tissue plasminogen activator (t-PA) has not been applied to acute symptomatic VA dissection.

The purpose of this report is to describe a case of spontaneous dissection of the vertebral artery, presenting clinically as basilar occlusion due to thromboembolism. Acute institution of treatment with t-PA was followed by a remarkable recovery of the patient.

\section{CASe Report}

A 49-year-old right-handed woman, with history of migraine headaches, experienced sudden onset of transient blurred vision and staggering gait as she was getting out of her car. A couple of hours later, she became nauseated and started to notice pain in the back of her head and neck, which continued to increase. Five hours after the onset of symptoms, she started to complain of the left-sided numbness and tingling followed by slurred speech, diplopia, and left-sided weakness. Her neurological examination revealed bilateral internuclear ophthalmoplegia, dysarthria, left hemiparesis, and left-sided sensory deficit. An urgent CT scan was interpreted as normal and negative for subarachnoid hemorrhage. The patient then underwent a lumbar puncture which was likewise normal.

Within the next thirty minutes, she became progressively dysarthric, obtunded, rapidly deteriorating to an unresponsive state with decerebrate posturing and apnea, requiring intubation. Given the patient's critical condition, cerebral arteriogram and magnetic resonance angiography were deferred. The clinical presentation of acutely evolving brainstem ischemia was suspected. Therefore, an intravenous dose of $100 \mathrm{mg}$ of t-PA (Activase, Genentech), according to the standard myocardial infarction protocol, was given seven hours from the onset of the first symptoms. Heparin was initiated thereafter.

The intravenous route of administration of t-PA was chosen because of the patient's rapid progression of vertebrobasilar ischemia, leaving no time for more invasive, intraarterial, intervention. In fact, the experience from the previous studies in Europe (see discussion) indicated that intravenous $t$-PA could be as successful as intraarterial administration in patients with basilar occlusion. In addition, no clinical trial for thrombolytic use in patients with basilar symptoms was available at the time.

Thirty minutes after the t-PA infusion, the patient began to regain consciousness and respond to verbal commands. Head MRI (Figure 1) on the next day showed increased signal on the T2 weighted images in the low anterior left cerebellar hemisphere, inferior right cerebellar hemisphere, anterior medulla, and inferior central pons. There was absence of flow void in the distal left vertebral artery and proximal basilar artery suggesting occlusions. Three dimensional phase contrast magnetic resonance angiography displayed the absence of signal in the distal left vertebral artery and the mid-basilar artery which was again suggestive for occlusive disease.

She further improved within the next couple of days and remained on heparin for three weeks following the t-PA injection. Conventional cerebral angiogram (Figure 2), three weeks after the onset of symptoms, revealed a dissection of the distal left intracranial vertebral artery, with aneurysmal dilatation, associated with severe stenosis of the vertebral artery at the level of the origin of the posterior inferior cerebellar artery (PICA). The right vertebral artery was small but with good flow. Good collateral flow via both posterior communicating arteries was noted.

From Division of Neurology, University of Nebraska Medical Center, Omaha,

Nebraska, (A.P.G.); Division of Neurology, Duke University Medical Center, Durham,

North Carolina, (C.G.); Department of Clinical Neurological Sciences, University

Hospital, London, Ontario, (V.H.).

RECEIVED JANUARY 30, 1996. ACCEPTED IN FINAL. FORM DECEMBER 13, 1996.

Reprint requests to: Andrew P. Gasecki, Division of Neurology, University of Nebraska Medical Center, 600 South 42nd Street, Omaha, Nebraska, USA 68198-2045 


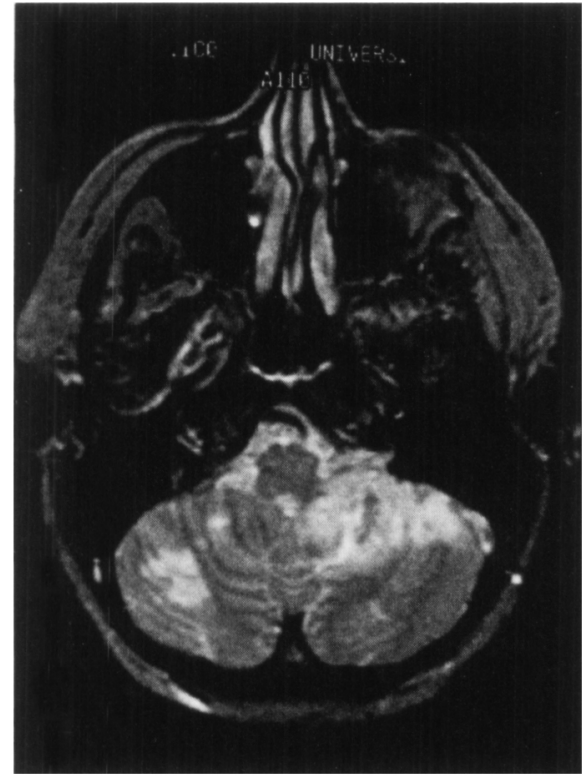

Figure 1: Axial T2-weighted MRI (TR 2800, TE 80) demonstrates increased signal in the anterior left and inferior right cerebellar hemispheres.

Subsequently, following a neurosurgical opinion, the patient was placed on ticlopidine. The second cerebral angiogram was performed six months after her initial event (Figure 3). Although no change in the size of the aneurysm was noted, for the previous months the patient became emotionally incapacitated, anxious about any type of activity, and housebound. A left suboccipital craniectomy with proximal, extracranial, occlusion, with two Sugita clips, of the left vertebral artery as it passed over the lamina of C-1, was performed. At surgery, the intracranial portion of the affected vertebral artery was quite widened and discolored. The PICA was involved in the area of the wide artery. No complications or any worsening of her preexisting deficit was experienced following surgery. She has remained in a stable condition for the past three years.

\section{DisCussion}

To our knowledge, the presented case is the first reported case of intravenous t-PA use in basilar occlusion due to embolism from the vertebral artery dissection. By the time the patient received the thrombolytic agent, she was unresponsive, apneic (requiring mechanical ventilation), and with decerebrate posturing. According to the recent evidence from Mayo Clinic, no neurologic improvement, beyond a locked-in syndrome, is expected in patients who need mechanical ventilation for acute basilar artery occlusion. ${ }^{8}$ The necessity of intubation may, therefore, serve as an early prognostic indicator for poor outcome to justify an institution of an aggressive treatment option.

There is no general agreement on the best management of patients with acute vertebral dissection. Anticoagulants have been traditionally used to prevent intraluminal thrombosis and subsequent thromboembolic complications during the period of spontaneous healing. ${ }^{27,9,10}$ Sherman et al. ${ }^{7}$ reported 24 cases of intracranial and extracranial vertebrobasilar dissections following an abrupt change in head position, with a high mortality rate (44.4\%) in the non-anticoagulated group of 9 patients as compared to the group of 6 anticoagulated patients with only one death $(16.7 \%)$. However, no controlled studies are available to confirm the efficacy of anticoagulants in vertebral dissections or basilar thrombosis.

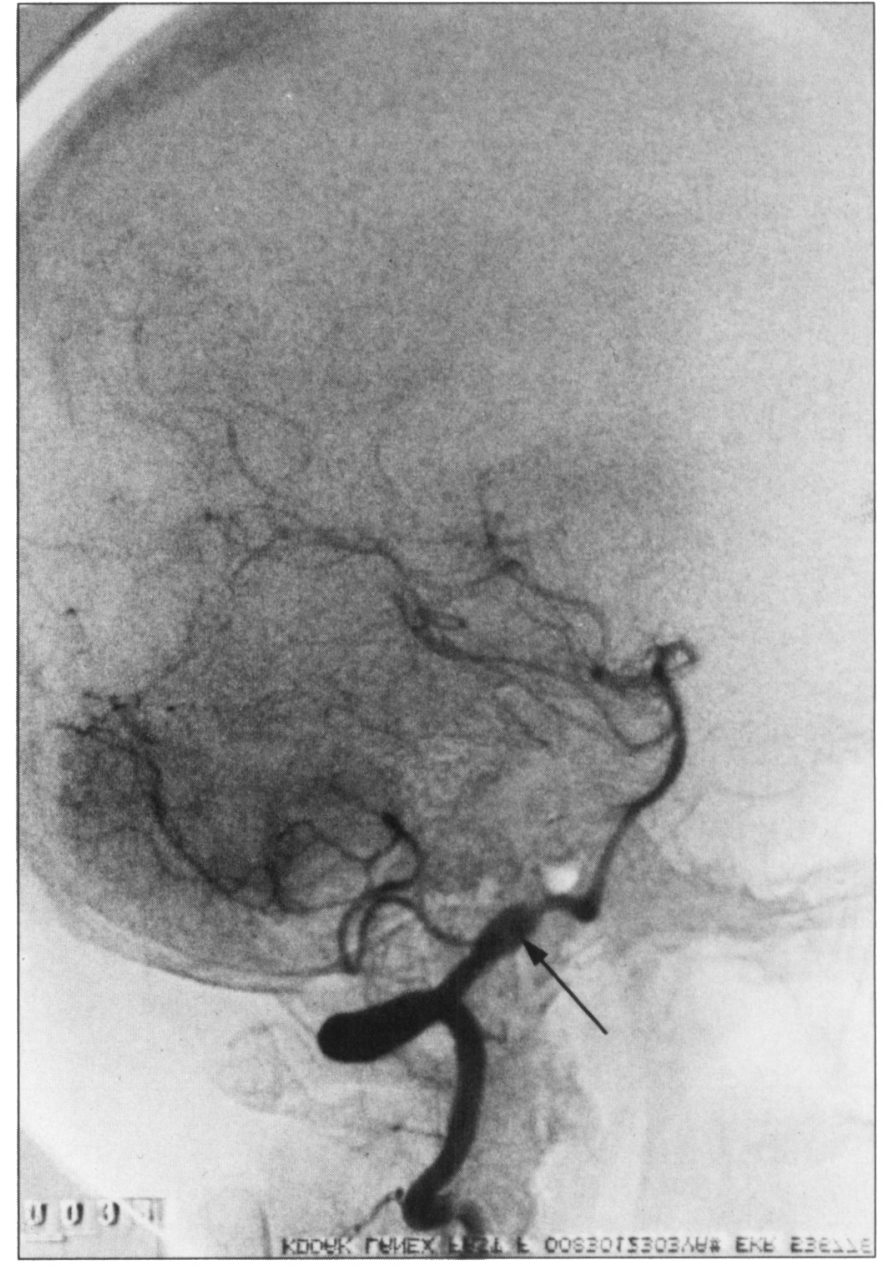

Figure 2: Cerebral angiogram three weeks after the event (left vertebral injection, lateral projection) shows focal dissection (arrow) of intracranial segment of the left vertebral artery at the origin of left PICA and deficient basilar artery filling.

The recently published results of the National Institute of Neurological Disorders and Stroke t-PA Study Group attested to the efficacy of t-PA in the treatment of acute ischemic stroke. ${ }^{11}$ However, for patients with basilar thrombosis, thus far, no data are available on the safest and the most effective route of thrombolytic administration. Beneficial outcome has been reported with superselective local intraarterial fibrinolysis with urokinase and streptokinase. ${ }^{12-17}$ Intravenous t-PA also has been used with the encouraging results. ${ }^{18}$ In fact, the systemic t-PA, used for acute occlusion of basilar artery, revealed comparable outcome results to those treated for the same condition but by the intraarterial route. ${ }^{17,18}$ Huemer et al. ${ }^{18}$ reported a series of 16 patients who received intravenous t-PA, at the identical dose to our patient $(100 \mathrm{mg})$, whose hemorrhagic complication was $12.5 \%$, comparable to the study by Brandt ${ }^{12}$ who reported a $14 \%$ hemorrhagic complication rate when the thrombolytic agent was used intraarterially for basilar artery thrombosis. These results may inspire to institute thrombolytics in patients with basilar ischemia, although, thus far, the fibrinolytic has not been used for vertebral artery dissection. None of the patients in the above studies, treated with various thrombolytic agents for basilar thrombosis, had a documented dissection. The only known cases 


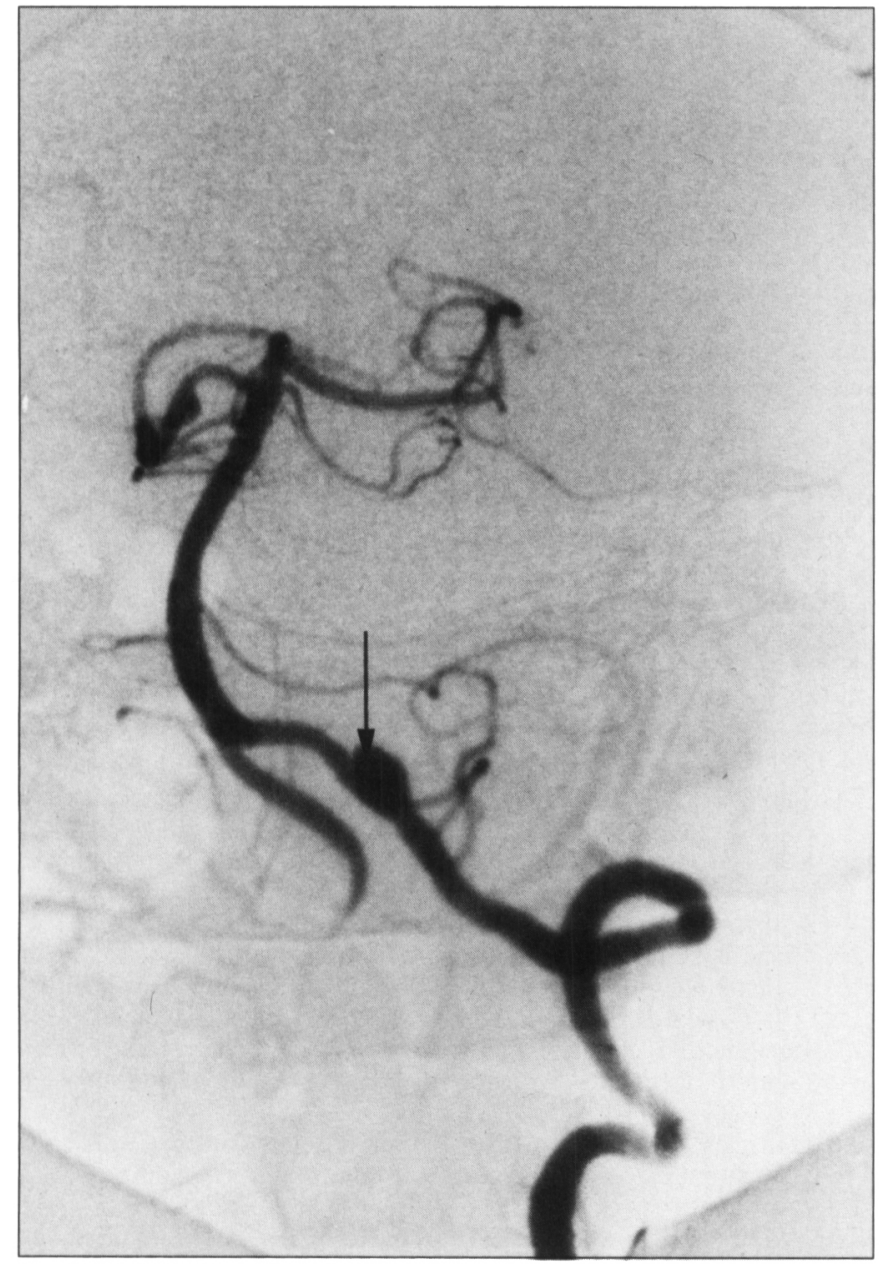

Figure 3: Cerebral angiogram six months after the event (left vertebral injection, anterior oblique projection) demonstrates dissecting aneurysm with pouch (arrow).

of thrombolytic use in arterial (carotid) dissection come from the study by Clark et al., who instituted intraarterial urokinase for intracranial vessel thrombolysis. ${ }^{19}$ The patients were successfully treated with the thrombolytic, injected through the catheter navigated through the acutely occluded carotid artery due to dissection, to lyse the embolus located distally to the area of dissection, in the middie cerebral artery territory. I may also speculate that in another case, reported by Zeumer et al., ${ }^{13}$ vertebral dissection may be suspected. The 27-year-old female, with symptoms of basilar thrombosis, had an angiographically documented right vertebral and upper basilar artery occlusions. After an intraarterial injection of streptokinase, she recovered.

The optimal time for institution of thrombolytic therapy is probably distinctly different between the patients presenting with the anterior and the posterior territory symptoms. The beneficial effect of t-PA was shown only if intravenous thrombolytic therapy is applied within three hours from the onset of symptoms in patients with a carotid territory ischemic stroke. For patients with basilar occlusion, such time-limit may not apply. The previous studies which showed the beneficial effect of thrombolytics in basilar thrombosis have utilized a 24- to 48hour window. ${ }^{12,14}$ The first ongoing prospective, randomized, Australian clinical trial of intraarterial urokinase for basilar artery thrombosis is using a 24-hour time window from the symptoms onset and the institution of treatment.

The value of heparin infusion following a thrombolytic administration is unknown in patients with basilar ischemia. For patients with acute ischemic stroke, according to the recently published and frequently quoted t-PA trial, ${ }^{11}$ no heparin is used after an intravenous t-PA injection. On the other hand, for patients with acute occlusion of the basilar artery, Huemer et al. ${ }^{18}$ reported a successful outcome in patients who received heparin after the intravenous t-PA injection. Identical combination of the thrombolytic and heparin was applied in our patient. In the previously reported studies that showed an improved outcome in patients presenting with the basilar ischemia, heparin infusion has been routinely administered following the intraarterial institution of thrombolytic agents. ${ }^{12,14}$

It needs to be emphasized that the use of t-PA or anticoagulants in patients with arterial dissections may be potentially risky. The anticoagulants have been reported to be associated with an arterial rupture ${ }^{20}$ and intracerebral hematoma. ${ }^{21,22}$ However, the literature gathered on coronary artery dissections indicates that the thrombolytic agents can be given with relative safety. ${ }^{23-26}$ Most reported cases reveal uneventful outcome in patients treated with thrombolytics, used for acute myocardial ischemia, prior to the angiographic discovery of arterial dissection. Paradoxically, there are several reported cases of coronary artery dissections treated with thrombolytic therapy to lyse the thrombus in the false lumen in the area of dissection, restoring the flow through the coronary artery. ${ }^{25,27,28}$ A typical example is a case of iatrogenic coronary dissection treated with intracoronary streptokinase, with uneventful recovery of the patient. ${ }^{25}$ On the other hand, an extension of a coronary dissection due to thrombolytic therapy has also been reported ${ }^{29}$ Unfortunately, the exact risk associated with thrombolytics in acute vertebral dissections cannot be estimated at the present time. Our report is the first case of systemic t-PA administration in acute vertebral artery dissection in a patient with the clinical symptoms of basilar occlusion.

The clinical presentation of dissection in the intracranial segment of the vertebral artery is that of ischemia or hemorrhage. The distinction has to be made between subarachnoid hemorrhage and vertebrobasilar ischemia if anticoagulant or thrombolytic is considered. Review of the published literature of Caplan et al. ${ }^{1}$ suggests that intracranial vertebral artery dissections with ischemic symptoms carry a much poorer prognosis than dissections associated with subarachnoid hemorrhage. Of 18 patients with subarachnoid hemorrhage and 10 patients with ischemic symptoms in the vertebrobasilar distribution, due to intracranial vertebral artery dissection, $22 \%$ death rate in the subarachnoid group was noted in contrast to $90 \%$ mortality in the ischemic group. ${ }^{1}$ However, the infrequency of occurrence of such dissections and selection bias for the cases gathered from literature review cannot provide any conclusion as to the actual mortality rates seen in clinical practice. If poor prognosis of intracranial dissections is confirmed by further studies, an aggressive therapy for non-hemorrhagic vertebral artery dissection may be justified and a clinical trial warranted.

The acute arterial dissections may eventually progress into dissecting aneurysms, as in our case. Dissecting aneurysms have been previously published only as case reports. ${ }^{30-41}$ Due to few non-surgically treated patients reported, the natural history of intracranial vertebral artery dissecting aneurysms with ischemic symptoms remains unknown. The operative intervention with proximal vertebral artery clipping or trapping has been advocated in order to 
promote thrombosis in the dissecting aneurysm. However, Friedman and Drake published the disappearance of non-hemorrhagic intracranial vertebral artery fusiform dissecting aneurysm managed conservatively for four years. ${ }^{30}$ Spontaneous resolution of intracranial dissecting aneurysm in the internal carotid and middle cerebral arteries on postmortem examination has been documented in children. ${ }^{42}$ It is only since 1977 when Yonas et al. ${ }^{31}$ reported the first vertebral angiographic and direct surgical observation of the intracranial vertebral artery dissecting aneurysm and, therefore, most subsequent reported cases were managed surgically.

A single case does not establish the safety of t-PA in arterial dissections. Therefore, we do not advocate administration of t-PA in unselected patients with vertebral arterial dissection. The decision to institute such treatment has to be carefully weighted depending on the severity and the prognosis of the patient's underlying condition. Although symptomatic vertebral dissections with basilar occlusion are rare, their prognosis appears poor which means that a therapeutic effect can be shown in a relatively few number of patients. Consequently, for patients in critical condition, a randomized controlled clinical trial may be both justifiable and feasible.

\section{ACKNOWLEDGEMENT}

Dr. Hachinski is a career investigator with the Heart and Stroke Foundation of Ontario.

\section{REFERENCES}

1. Caplan LR, Baquis GD, Pessin MS, et al. Dissection of the intracranial vertebral artery. Neurology 1988; 38: 868-877.

2. Hinse $P$, Thie A, Lachenmayer L. Dissection of the extracranial vertebral artery: report of four cases and review of the literature. $J$ Neurol Neurosurg Psychiatry 1991; 54: 863-869.

3. Youl BD, Coutellier A, Dubois B, Leger JM, Bousser MG. Three cases of spontaneous extracranial vertebral artery dissection. Stroke 1990; 21: 618-625.

4. Leys D, Lesoin F, Pruvo JP, et al. Bilateral spontaneous dissection of extracranial vertebral arteries. J Neurol 1987; 234: 237-240.

5. Mas J-L, Bousser MG, Hasboun D, Laplane D. Extracranial vertebral artery dissections: a review of 13 cases. Stroke 1987; 18: 1037-1047.

6. Katirji MB, Reinmuth OM, Latchaw RE. Stroke due to vertebral artery injury. Arch Neurol 1985; 42: 242-248.

7. Sherman DG, Hart RG, Easton JD. Abrupt change in head position and cerebral infarction. Stroke 1981; 12: 2-6.

8. Wijdicks E, Scott JP. Outcome in patients with acute basilar artery occlusion requiring mechanical ventilation. Stroke 1996; 27: 1301-1303.

9. Bogousslavsky J, Despland P, Regli F. Spontaneous carotid dissection with acute stroke. Arch Neurol 1987; 44: 137-140.

10. Fisher CM, Ojemann RG, Robertson GH. Spontaneous dissection of cervico-cerebral arteries. Can J Neurol Sci 1978; 5: 9-19.

11. The National Institute of Neurological Disorders and Stroke rt-PA Stroke Study Group. Tissue plasminogen activator for acute ischemic stroke. N Engl J Med 1995; 333: 1581-1587.

12. Brandt T, Von Kummer R, Muller-Kuppers M, Hacke W. Thrombolytic therapy of acute basilar artery occlusion. Variables affecting recanalization and outcome. Stroke 1996; 27: 875-881.

13. Zeumer $\mathrm{H}$, Hacke W, Ringelstein EB. Local intraarterial thrombolysis in vertebrobasilar thromboembolic disease. Am J Neuroradiol 1983; 4: 401-404.

14. Hacke W, Zeumer H, Ferbert A, Bruckmann H, Del Zoppo GJ. Intraarterial thrombolytic therapy improves outcome in patients with acute vertebrobasilar occlusive disease. Stroke 1988; 19: 1216-1222.

15. Bruckmann H, Ferbert A, Del Zoppo GJ, Hacke W, Zeumer H. Acute vertebral-basilar thrombosis. Angiologic-clinical comparison and therapeutic implications. Acta Radiol Suppl 1986; 369: 38-42.
16. Nenci GG, Gresele P, Taramelli M, Agnelli G, Signorini E. Thrombolytic therapy for thromboembolism of vertebrobasilar artery. Angiology 1983; 34: 561-571.

17. Zeumer H, Freitag H-J, Zanella F, Thie A, Arning C. Local intraarterial fibrinolytic therapy in patients with stroke: urokinase versus recombinant tissue plasminogen activator (r-TPA). Neuroradiology 1993; 35: 159-162.

18. Huemer M, Niederwieser V, Ladurner G. Thrombolytic treatment for acute occlusion of the basilar artery. J. Neurol Neurosurg Psychiatry 1995; 58: 227-228.

19. Clark WM, Barnwell SL, O'Neill OR, et al. Successful middle cerebral artery thrombolysis by microcatheter navigation through an occluded internal carotid artery [Abstract]. Stroke 1995; 26: 12 and J Neurosurg 1996; 84: 387-392.

20. Adams HP Jr, Aschenbrener CA, Kassell NF, Ansbacher L, Cornell $\mathrm{SH}$. Intracranial hemorrhage produced by spontaneous dissecting intracranial aneurysm. Arch Neurol 1982; 39: 773-775.

21. Hochberg FH, Bean C, Fisher CM, Robertson GH. Stroke in a 15year-old girl secondary to terminal carotid dissection. Neurology 1975; 25 : 725-729.

22. Kunze ST, Schiefer W. Angiographic demonstrations of dissecting aneurysm of the middle cerebral artery. Neuroradiology 1971; 2: 201-206.

23. Benham $R$, Tillinghast $S$. Thrombolytic therapy in spontaneous coronary artery dissection. Clin Cardiol 1991; 14: 611-614.

24. Vacek J, McKiernan T. Intracoronary streptokinase for acute coronary artery dissection. N Engl J Med 1984; 310: 1187.

25. Lee T-M, Liau C-S. Spontaneous coronary artery dissection in an elderly woman with acute inferior myocardial infarction. A case report. Angiology 1995; 46: 847-851.

26. Blanc P, Hoffman P, Latour F, et al. Spontaneous dissection of the distal anterior intraventricular artery during intravenous thrombolysis. Ann Cardiol Angeiol Paris 1991; 40: 427-428.

27. Ramamurti S, Mahrer PR, Magnusson P, et al. Idiopathic coronary artery dissection. A rare in vivo diagnosis. Clin Cardiol 1985; 8: $57-60$.

28. Gonzales JI, Hill JA, Conti CR. Spontaneous coronary artery dissection treated with percutaneous transluminal angioplasty. Am J Cardiol 1989; 63: 885-886.

29. Buys EM, Suttorp MJ, Morshuis WJ, Plokker HW. Extension of a spontaneous coronary artery dissection due to thrombolytic therapy. Cathet Cardiovasc Diagn 1994; 33: 157-160.

30. Friedman AH, Drake CG. Subarachnoid hemorrhage from intracranial dissecting aneurysm. J Neurosurg 1984; 60: 325-334.

31. Yonas H, Agamanolis D, Takaoka Y, White RJ. Dissecting intracranial aneurysms. Surg Neurol 1977; 8: 407-415.

32. Shimoji T, Bando K, Nakajima K, Ito K. Dissecting aneurysm of the vertebral artery. Report of seven cases and angiographic findings. J Neurosurg 1984; 61: 1038-1046.

33. Berger MS, Wilson CB. Intracranial dissecting aneurysms of the posterior circulation. Report of six cases and review of the literature. J Neurosurg 1984; 61: 882-894.

34. Yamaura A. Diagnosis and treatment of vertebral aneurysms. J Neurosurg 1988; 69: 345-349.

35. Mokri B, Houser OW, Sandok BA, Piepgras PG. Spontaneous dissections of the vertebral arteries. Neurology $1988 ; 38: 880-885$

36. Senter HJ, Sarwar M. Nontraumatic dissecting aneurysm of the vertebral artery. Case report. J Neurosurg 1982; 56: 128-130.

37. Kulla L, Deymeer F, Smith TW, Weiner M, Mullins III TF. Intracranial dissecting and saccular aneurysms in polycystic kidney disease. Report of a case. Arch Neurol 1982; 39: 776-778.

38. Manz HJ, Luessenhop AJ. Dissecting aneurysm of intracranial vertebral artery: case report and review of literature. J Neurol 1983; 230: $25-35$.

39. Sasaki O, Ogawa H, Koike T, Koizumi T, Tanaka R. A clinicopathological study of dissecting aneurysms of intracranial vertebral artery. J Neurosurg 1991; 75: 874-882.

40. Tanaka K, Waga S, Kojima $T$, et al. Non-traumatic dissecting aneurysms of the intracranial vertebral artery. Report of six cases. Acta Neurochir (Wien) 1989; 100: 62-66.

41. Yamaura A, Watanabe Y, Saeki N. Dissecting aneurysms of the intracranial vertebral artery. J Neurosurg 1990; 72: 183-188.

42. Nass R, Hays A, Chutorian A. Intracranial dissecting aneurysms in childhood. Stroke 1982; 13: 204-207. 